\title{
Non endoscopic endonasal dacryocystorhinostomy versus external dacryocystorhinostomy
}

\section{Sharma BR}

Consultant Ophthalmologist and Chief Oculoplasty Unit, Lumbini Eye Institute, Siddharthanagar, Nepal, Associate Professor, National Academy of Medical Sciences, Kathmandu, Nepal.

\begin{abstract}
Aims and Objectives: To compare the success rates of non endoscopic endonasal dacryocystorhinostomy and conventional external dacryocystorhinostomy for the surgical management of primary acquired nasolacrimal duct obstruction.

Materials and methods: A retrospective, nonrandomized, comparative interventional case series of 302 patients who underwent either endonasal or external dacryocystorhinostomy over a period of 2 years. All surgeries were performed by a single surgeon and patients with primary nasolacrimal duct obstruction with a minimum of 6 months post operative follow up were included in the study. While external dacryocystorhinostomy was performed using traditional technique, endonasal dacryocystorhinostomy was performed using direct method of nonendoscopic visualization.

Results: Of the 302 cases included in the study 165 patients had endonasal dacryocystorhinostomy whereas 137 underwent external dacryocystorhinostomy. Success was defined by resolution of symptoms of tearing, a negative fluorescein dye disappearance test and patency of the canalicular system on lacrimal irrigation. In the external dacryocystorhinostomy group $124(90.5 \%)$ patients had surgical success whereas $146(88.5 \%)$ of the endonasal dacryocystorhinostomy patients had successful outcome. The overall success rate was $89.4 \%$, and the difference of surgical success between the two groups was not statistically significant ( $P=0.57$ ).

Conclusion: Non endoscopic endonasal dacryocystorhinostomy gives surgical results comparable to those of external dacryocystorhinostomy and is a viable alternative where dacryocystorhinostomy is indicated for primary acquired nasolacrimal duct obstruction.
\end{abstract}

Key words: Endonasal Dacryocystorhinostomy (ENDCR), External Dacryocystorhinostomy (EXDCR), Primary acquired nasolacrimal duct obstruction (PANLDO)

The transcutaneous route for external described in 1904, and since has become the standard procedure for the management of nasolacrimal duct obstruction ${ }^{1}$. Though Caldwell had described the transnasal route in 1893, it is only in the last two decades that endonasal dacryocystorhinostomy (ENDCR) has become popular with the development of better instrumentation techniques ${ }^{2}$.

Early surgeons performed ENDCR using endoscope for visualization and endolaser for cutting ${ }^{3,4}$. As lasers are expensive and have shown to have lower success rates, surgeons have converted to mechanical means for making the bony and mucosal openings ${ }^{5-7}$. Others have employed alternative methods for visualization like operating microscopes and operating loupes. With advancement in instrumentation more surgeons now perform non laser ENDCR with the results ranging from $83 \%$ to $96 \% \%^{5,7-9}$.
This study reviews 302 cases of dacryocystorhinostomy (DCR), with minimum follow up period of 6 months, performed by a single surgeon over a period of 2 years. Surgical outcome between two groups of patients, non endoscopic, non laser, endonasal dacryocystorhinostomy (ENDCR) and external dacryocystorhinostomy (EXDCR) is compared.

\section{Materials and methods}

Chart review was performed of those who underwent DCR for primary acquired nasolacrimal duct obstruction (PANLDO) from February 2004 to February 2006. All patients attending the oculoplastic clinic at Lumbini Eye Institute (LEI) with history of epiphora underwent

Correspondence

Dr. Basant Raj Sharma

Lumbini Eye Institute

Siddharthanagar-3

Rupandehi, Nepal

E-mail: docbrs@gmail.com 
standard lacrimal workup, including fluorescein dye disappearance test (FDDT), probing and irrigation of the lacrimal system. Dacrocystography was not performed but all patients underwent ENT consultation to rule out nasal pathology. Out of the 427 charts reviewed, 302 were eligible for inclusion in the study. All surgeries were performed by one surgeon (the author).

Both ENDCR and EXDCR surgeries were performed under local anesthesia with sedation in form of Lorazepam $2 \mathrm{mg}$ given orally one hour before surgery. Infratrochlear and infraorbital nerve block were given using lidocaine 2\% with 1:100,000 epinephrine. Ribbon gauze soaked in $4 \%$ lidocaine and Xylometazoline $0.05 \%$ (50:50) solution was used to pack the nasal cavity. In addition lidocaine 2\% with 1:100,000 epinephrine was injected in the nasal mucosa at the site of osteotomy, in case of ENDCR. Surgery was performed under sterile conditions.

\section{Surgical Technique: EXDCR}

A vertical $15 \mathrm{~mm}$ curvilinear skin incision was given 8 $\mathrm{mm}$ from the medial canthus. Using blunt dissection the orbicularis fibers were dissected until medial canthal tendon and the anterior lacrimal crest was exposed along the incision line. The overlying periosteum was incised and dissected from the lacrimal sac fossa until the maxillo-lacrimal suture line was identified. Using a freer periosteal elevator bony opening was made along the suture line and enlarged to an average diameter of $15 \mathrm{~mm}$ using Kerrison punch. A probe passed through the canaliculus was used to identify the lacrimal sac which was then incised longitudinally and anterior flap fashioned, whereas the posterior flap was excised. A U-shaped nasal mucosal flap was created based anteriorly and trimmed to match the anterior lac sac flaps. All cases underwent silastic tube intubation over which the anterior flaps were sutured using 6-0 vicryl. The skin incision was closed in a single layer with running 6-0 vicryl suture.

\section{Surgical Technique: EN-DCR}

EN-DCR was performed using the non laser, nonvideoendoscope technique as described by Dolman $^{8,10}$. Both puncta were dilated and vitreoretinal light pipe threaded through the canaliculus into the lacrimal sac that was connected to a light source. Nasal cavity was visualized using operating loupes and headlight (Fig 1).

The transilluminated lacrimal sac area was identified and using a myringotomy sickle knife a vertically oval area of the overlying mucosa was incised. Cottle periosteal elevator was used to dissect the mucosa from the bone and Weil-Blaskesley ethmoid forceps used to excise the mucosa thereby exposing the transilluminated lacrimal sac fossa. Freer elevator was used to make an opening in the maxillary-lacrimal bone suture line. A 3 $\mathrm{mm}$ kerrison ronguer was used to enlarge the osteotomy anteriorly and superiorly until the tented lacrimal sac was visualized adequately (Fig 2).

Sickle knife was used to open the tented sac and once again, the opening enlarged until the medial aspect of the lacrimal sac was completely excised and the internal ostium with the light pipe visualized. Remnant tags of the sac were excised using Rhoton micro pituitary forceps followed by silastic tube intubation. Postoperative nasal packing was not done routinely.

Patients stayed overnight at the hospital and were discharged the next day. At the time of discharge, they were given a course of oral antibiotic for one week. Topical steroid/antibiotic eye drops were prescribed Q.I.D. for two weeks along with nasal decongestant drops T.I.D. for one week. EXDCR patients were asked to return within two weeks for suture removal and assessment, whereas EN-DCR patients were asked to come for assessment in a month's time.

Silicone stents were removed at three months and after six months follow up patients were evaluated for resolution of symptoms, tear meniscus height, FDDT, and irrigation through the canaliculus to determine the surgical outcome.

\section{Results}

During the study period, out of the 427 files reviewed 302 patients were included in the study. The reason for exclusion was primarily inadequate follow up. Other reasons for exclusion were surgery (EXDCR) performed by surgeons other than the author, canalicular and sac pathology, and NLD obstruction due to trauma. Out of the 302 patients $165(54.6 \%)$ had undergone ENDCR and 137 EX-DCR (45.4\%). In bilateral cases, only the side that was operated upon during the study period or that which was operated first was included.

The number of females undergoing surgery was much higher than male with a ratio of 3.6:1 (Table 1). The youngest patient was 14 years old and oldest 70 years of age. The mean age for surgery was $34.46( \pm 11.75)$ years.

By the above criteria out of the 137 EXDCR patients $124(90.5 \%)$ had successful out come whereas $13(9.5 \%)$ were failures. Likewise of the 165 ENDCR patients included in the study $146(88.5 \%)$ had successful, and $19(11.5 \%)$ had failed outcome (Table 2). Using Chi Square test (SPSS Inc.,Chicago,IL) the difference in the success rates of EXDCR and ENDCR $(P=0.57)$ were not statistically significant. 
Presenting complaints at the time of surgery were primarily epiphora and discharge with an average duration of 35 months. There was no significant difference in laterality of surgery, with 149 (49.3\%) and $153(50.7 \%)$, performed on the right and left side respectively. Surgical outcome was determined after removal of silastic tube and a minimum of six months follow up. The mean postoperative period for stent removal was 19.36 weeks $( \pm 8.6)$ and mean follow up period was 34.36 weeks $( \pm 18.67)$. Success was defined by resolution of symptoms of tearing, a negative FDDT test and patency of the lacrimal system on irrigation. Failure was determined by non-resolution of symptoms

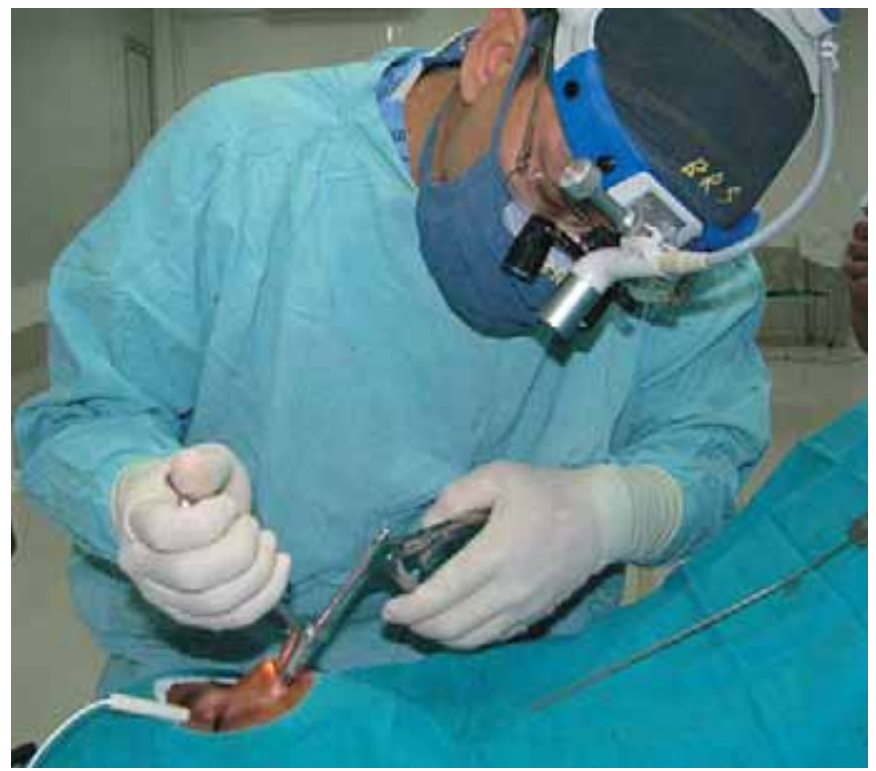

Fig 1: Transillumination of the lacrimal sac with insertion of a vitreoretinal light pipe.

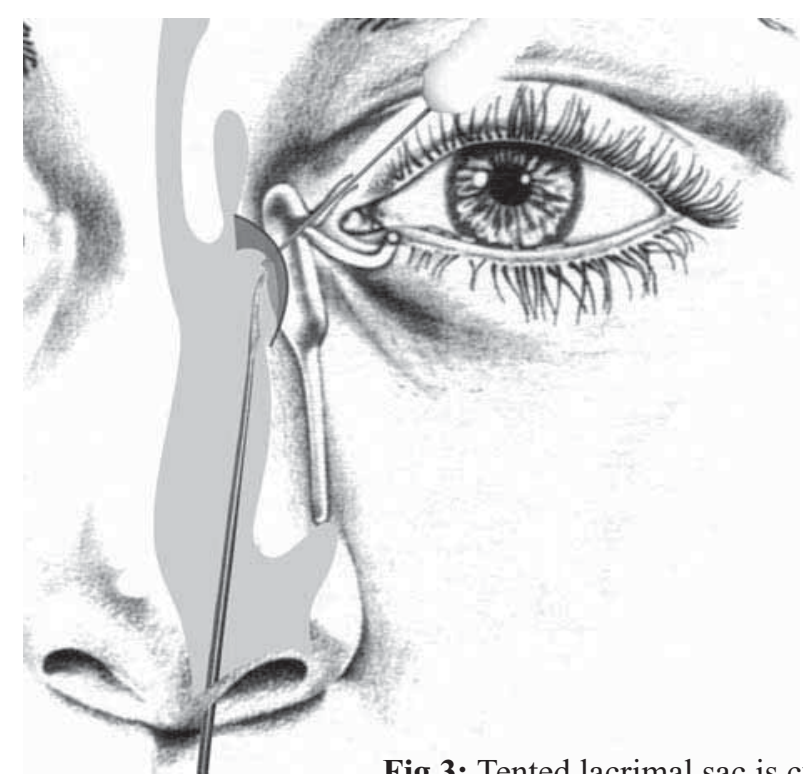

Fig 3: Tented lacrimal sac is cut open using a sickle knife. and blocked system on lacrimal irrigation. Those patients with partially patent lacrimal system and persistent epiphora with positive FDDT were considered failures.

Post operative complications were uncommon with two ENDCR patients with major nasal haemorrhage that required extended hospitalization. Four patients had wound infection and gaping requiring resuturing. The most common late complication was canalicular cut through by the silastic tube. This was observed in 24 $(7.9 \%)$ of patients at the time of removal of the stent. Other complications were nasal mucosa synechial fibrosis 8 (2.6\%), all of whom were ENDCR cases.

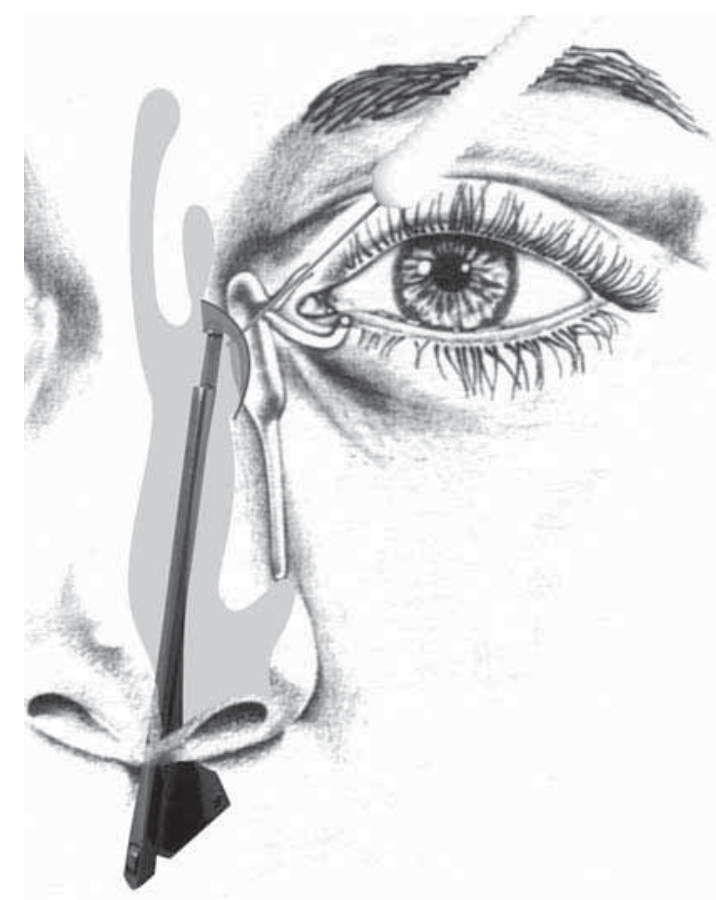

Fig 2: Osteotomy using kerrison rongeur to expose the underlying lacrimal sac. 
Table 1: Demographics of External and Endonasal Dacryocystorhinostomy patients

\begin{tabular}{|l|c|c|c|}
\hline GENDER & EXDCR & ENDCR & TOTAL \\
\hline Male & 35 & 30 & 65 \\
\hline Female & 102 & 135 & 237 \\
\hline Total & 137 & 165 & 302 \\
\hline
\end{tabular}

Table 2: Surgical Outcome for Endonasal and External Dacryocystorhinostomy

\begin{tabular}{|l|c|c|c|c|c|c|}
\hline & \multicolumn{2}{|c|}{ SUCCESS } & \multicolumn{2}{c|}{ FAILURE } & \multicolumn{2}{c|}{ TOTAL } \\
\hline & $\mathbf{n}$ & $\mathbf{\%}$ & $\mathbf{n}$ & $\mathbf{\%}$ & Count & \% \\
\hline EXDCR & 124 & $90.5 \%$ & 13 & $9.5 \%$ & 137 & $100.0 \%$ \\
\hline ENDCR & 146 & $88.5 \%$ & 19 & $11.5 \%$ & 165 & $100.0 \%$ \\
\hline Total & 270 & $89.4 \%$ & 32 & $10.6 \%$ & 302 & $100.0 \%$ \\
\hline
\end{tabular}

$P=0.569$ Chi-square test

\section{Discussion}

In the last decade or so, ENDCR has come under great scrutiny. The use of vitreoretinal light pipe for transillumination of the lacrimal sac area, along with the development of better instrumentation, has resulted in renewed interest in this technique ${ }^{4}$. Proponents of endonasal DCR cite surgical success rates comparable to those of EXDCR, along with benefits of lack of skin incision and associated wound complications. The surgical operative times are shorter, tissue damage is limited due to optimum placement of osteotomy site and postoperative care minimized.

Disadvantages of ENDCR include lower success rates, expensive equipment, need for general anesthesia, steep learning curve and the fact that EXDCR gives excellent surgical success rates. As our knowledge and understanding of nasal anatomy concerning ENDCR improves, we are becoming more aware of the factors that are responsible for the lower outcome rates. Studies in the past show that laser assisted ENDCR has lower success rates of $60-80 \%$ range $e^{5,6,18}$. This has resulted in a shift towards mechanical endonasal DCR (MENDCR) using rongeurs and microburrs. Tsirbas et. al in their study reported anatomic patency of $96.8 \%$ in MENDCR group compared to $100 \%$ in EXDCR group ${ }^{7}$. Further more even with the criterion of functional patency, the success rate in MENDCR group was $93.5 \%$. Similarly using non endolaser techniques Dolman has in his series of 349 cases found no significant difference in outcome of ENDCR and EXDCR ${ }^{8}$. Nasal endoscopes are expensive and not essential for ENDCR. Various studies demonstrate that ENDCR with direct visualization, as described in this study, are effective methods for the treatment of PANLDO via the transnasal route r,10,13,14. $^{\text {. }}$ One report that evaluated various techniques of ENDCR using endoscopes, microscopes and direct visualization, found no difference in the success rates ${ }^{11}$.
Many surgeons believe that general anesthesia is essential for performing ENDCR. This is not true, as we have been performing ENDCR under local anesthesia for the last four years. Though this study has not specifically addressed the issue of anesthesia and patient comfort, there are studies that show that discomfort during ENDCR under local anesthesia is not a major problem $8,17,18$.

In our study, the morbidity associated with ENDCR is very low and studies in the past have shown that complication rates of ENDCR are no higher than those for $\mathrm{EXDCR}^{8,11,12,19-21}$. Most common complication in late postoperative period was silastic tube cut through, or "cheese wiring", of the canaliculi seen in 24 patients $(7.9 \%)$ at the time of stent removal. Out of these seven were EXDCR patients, one of whom eventually was a failure, and 17 were ENDCR. The higher number of cut through indicates a relative inexperience with stenting in ENDCR in the early cases. Out of the 17 cases, six ENDCRs failed. It was observed that more severe the cut through, that is more than half the length of the canaliculus, the higher the chances of failure. The other complication observed was nasal mucosal synechiae between ostium and septum was seen in eight (2.6\%) patients all of whom underwent ENDCR. Out of these, three were failure cases. It has been frequently reported in literature that nasal mucosal synechiae is associated with a higher frequency of failure cases ${ }^{11,18,21}$. Lastly in ENDCR there is less disruption of medial canthal anatomy and lacrimal pump function ${ }^{4,7,12}$. Lacrimal scintillography studies done in anatomically patent ENDCR and EXDCR, show positivity in 90\% ENDCR patients compared to only $76 \%$ in EXDCR group ${ }^{7,15}$.

Nevertheless there are patients where EXDCR is indicated, including NLD block secondary to trauma and congenital deformities. We also avoid ENDCR 
in patients with canalicular pathology and those with atrophic lacrimal sacs. In our experience, routine use of stents is beneficial especially in cases of ENDCR as it helps to maintain the patency of the internal ostium and keep the flaps of lacrimal sac from sealing together ${ }^{20-22,24}$. It is a false belief that small osteotomy results in rhinostomy failure rather it seems that a small osteotomy leads to small anastomosis of the sac and mucosa resulting in "sumping" with retention of the "3-compartment system, and subsequent failure ${ }^{22,23}$.

This was a retrospective study with patient file review and therefore associated with the inherent drawbacks of such studies, including patient selection bias and inadequate follow up. Nevertheless, to our knowledge, this is the first comparative study of ENDCR and EXDCR reported in Nepal. As mentioned earlier out of the 427 files review only 302 were eligible for inclusion. Which mean that more than a quarter of the patients were dropped from the study, primarily due to inadequate follow up. Therefore a prospective study of better design with adequate follow-up, we feel would yield better surgical outcome

\section{Conclusion}

We have been performing non-endoscopic ENDCR in our center for the last four years. We recommend ENDCR as primary surgical procedure in PANLDO with normal or large lacrimal sacs and adequate nasal space. In our experience patients with fibrotic lacrimal sacs, canalicular pathology, and posttraumatic NLD obstruction are poor candidates for ENDCR. In addition, we prefer EXDCR for secondary revisional surgery for failed DCR cases.

\section{Acknowledgement}

I would like to express my sincere thanks to Mr. Susan Shrestha (HKI, Nepal) for helping with the statistical analysis.

\section{References}

1. Toti A. Nuovo metado conservatore di cura radicale delte suppurazioni chronicle del sacco lacrimale (dacriocistorinostomia). Clin Mod Firenza 1904;10:385-7.

2. Cadwell GW. Two new operations for obstruction of the nasal duct, with preservation of the canaliculi, and with an incidental description of a new lacrimal probe. Am J Ophthalmology 1893;10:189-93.

3. McDonough M, Meiring JH. Endoscopic transnasal dacryocystorhinostomy. J Laryngol Otol 1989;103:585-7.

4. Massaro BM, Gonnering RS, Harris GJ. Endonasal laser dacryocystorhinostomy. A new approach to nasolacrimal duct obstruction duct obstruction. Arch Opthalmol 1990;108:1172-6.

5. Durvasula VS, Gatland DJ. Endoscopic dacryocystorhinostomy: long term results and evolution of surgical technique. J Laryngol Otol 2004;118:267-9.

6. Mirza S, Al-Barmani A, Douglas SA, et al. A retrospective comparison of endonasal KTP laser dacryocystorhinostomy versus external dacryocystorhinostomy. Clin Otolaryngol 2002;27:347-51.

7. Tsirbas A, Davis G, Wormald PJ. Mechanical endonasal dacryocystorhinostomy versus external dacryocystorhinostomy versus external dacryocystorhinostomy. Ophthal Plast Reconstr Surg 2004;20:50-6.

8. Dolman PJ. Comparison of external dacryocystorhinostomy with nonlaser endonasal dacryocystorhinostomy. Ophthalmology 2003;110:78-84.

9. Nussbaumer M, Schreiber S, Yung MW. Concomitant nasal procedures in endoscopic dacryocystorhinostomy. J Laryngol Otol 2004;118:628-32.

10. Dolman PJ. Techniques in endonasal dacryocystorhinostomy. In: Guthoff R, Katowitz JA, editors. Oculoplastics and Orbit. Heidelberg:Springer-Verlag; 2006. p. 71-82.

11. Woog J, Kennedy RH, Custer PL, et al. Endonasal dacryocystorhinostomy. A report by the American Academy of Ophthalmology. Ophthalmology 2001;108:2369-77.

12. Simon GB, Joseph J, Lee S, et al. External versus endoscopic dacryocystorhinostomy for acquired nasolacrimal duct obstruction in a tertiary referral center. Ophthalmology 2005;112:1463-8.

13. Jokinen K, Karja J. Endonasal dacryocystorhinostomy. Arch Otolaryngol 1974;100:41-4.

14. Tutton MK, O' Donnell NP. Endonasal laser dacryocystorhinostomy under direct vision. Eye 1995;9:485-7.

15. Wormald PJ, Tsirbas A. Investigation and endoscopic treatment for functional and anatomical obstruction of the nasolacrimal duct system. Clin Otolaryngol 2004;29:352-6.

16. Duffy MT. Advances in lacrimal surgery. Opin Ophthalmol 2000;11:352-6.

17. Tripathi A, Lesser THJ, O' Donnell NP, et al. Local anesthetic endonasal endoscopic laser dacryocystorhinostomy:analysis of patient's acceptability and various factors affecting the success of this procedure. Eye 2002;16:146-9. 
18. Moore WMH, Bentley CR, Olver JM et.al. Functional and anatomic results after two types of endoscopic endonasal dacryocystorhinostomy: surgical and holium laser. Ophthalmology 2002;109:1575-82.

19. Cokkeser Y, Evereklioglu C, Er H. Comparative external versus endoscopic dacryocystorhinostomy: results in 115 patients. Otolaryngol Head Neck Surg 2000;123:48391.

20. Massegur H, Trias E, Adema JM. Endoscopic dacryocystorhinostomy: Modified technique. Otolaryngol Head Neck Surg 2004;130:39-46.
21. Fayet B, Racy E, Assouline M. Complications of standardized endonasal dacryocystorhinostomy with unciformectomy. Opthalmology 2004; 111:837-45.

22. Baldeschi L, Trenite GJN, Hintschich C. The intranasal ostium after external dacryocystorhinostomy and the internal opening of the lacrimal canaliculi. Orbit 2000;19:81-6.

23. Rose GE. The lacrimal paradox: Toward a greater understanding of success in lacrimal surgery. Ophthal Plast Reconstr Surg 2004;40:262-5.

24. Goldberg RA. Endonasal dacryocystorhinostomy: Is it really less successful. Arch Ophthalmol 2004;122:108-10. 